\title{
Reduced Meloidogyne ethiopica Parasitism in Vitis vinifera Grafted on Six Resistant Rootstocks Under Field and Greenhouse Conditions
}

\author{
J. C. Magunacelaya, R. Mancilla, and S. González-Bernal, Instituto de Biología, Pontificia Universidad Católica de Valparaíso, Curauma, \\ Valparaíso, Chile
}

\begin{abstract}
Meloidogyne ethiopica, an aggressive nematode, causes significant economic losses to Vitis crops. Rootstocks can successfully manage phytoparasitic nematodes. However, no studies exist on M. ethiopica-resistant rootstocks under field conditions. This study assessed the resistance of six Vitis rootstocks to M. ethiopica under field and greenhouse conditions. The number of galls and eggs in vine roots, quantity of second stage juveniles and males in $250 \mathrm{ml}$ of soil, root weight, and shoot weight were determined for the Harmony, SO4, 101-14 MG, 110R, 3309C, and Kober 5BB rootstocks, and the own-root Chardonnay variety as a control.

In the field, Harmony, SO4, 101-14 MG, Kober 5BB, and 110R were highly resistant to nematode parasitism and reproduction. In turn, 3309C was the least resistant rootstock. In the greenhouse, all rootstocks similarly limited M. ethiopica attack and reproduction. In both conditions, Chardonnay was the most susceptible vine to nematode attack, with high quantities of galls, eggs, and nematode reproduction. In conclusion, most of the evaluated rootstocks reduced M. ethiopica parasitism. Harmony, SO4, 101-14 MG, 110R, and Kober 5BB rootstocks are options for vineyard use, with final selection dependent on winegrower requirements.
\end{abstract}

Phytoparasitic nematodes are a significant problem in the wine industry and cause estimated losses of US $\$ 78$ billion worldwide in agricultural sectors (Smiley 2005). Of the nematode genera that affect grapevines, the Meloidogyne genus is one of the most harmful as it can affect a wide range of hosts and is difficult to control (Karssen and Moens 2006). These nematode species are associated with decreased production and the death of grapevines, with Chardonnay wine grapes being particularly susceptible to attack by this parasite (Rivera and Aballay 2008). Within this genus, Meloidogyne ethiopica Whitehead, 1968 is a recognized serious threat to vineyards and other crops due to high aggressiveness and harmful effects (Carneiro et al. 2007), severely affecting harvests in Chile and other South American countries (Hunt and Handoo 2009) such as Brazil (Carneiro et al. 2003) and Peru (Murga-Gutiérrez et al. 2012). Moreover, this species has been detected in various African countries, including Tanzania, Ethiopia, Kenya, Mozambique, South Africa, and Zimbabwe, as well as some Mediterranean countries, including Greece (Conceição et al. 2012), Slovenia (Širca et al. 2004; Strajnar et al. 2009), and Turkey (Aydınlı et al. 2013). This nematode has apparently not perfected its parasitic capacity and attacks plants until causing death (Carneiro et al. 2004; Magunacelaya 2004). In 2011, the pathogenicity and aggressiveness of this nematode led to its placement on the alert list of the European and Mediterranean Plant Protection Organization (EPPO 2015).

Resistant rootstocks can be used to develop root systems that can grow in coexistence with phytoparasitic nematodes (Anwar et al. 2000). Rootstock resistance is related to host properties that reduce pathogen density, such as inhibiting, restricting, delaying, or altering nematode development. In leading wine-producing countries, such as the U.S.A. (i.e., California), Australia, South Africa, and Chile, rootstocks with nematode resistance or tolerance have been evaluated under controlled and field conditions. Some of the most successful rootstocks in this regard include Dogridge, Salt Creek (Ramsey), 1613, 1616, 5A, Harmony, Freedom, Schwartzmann, SO4, and Kober 5BB (Ferris et al. 2012; Pérez 1991). These nematode-resistant rootstocks have been used worldwide for decades and have been widely studied, particularly in relation to the four most common species

Corresponding author: Juan Carlos Magunacelaya;

E-mail: juan.magunacelaya@pucv.cl

Accepted for publication 18 January 2017.

(C) 2017 The American Phytopathological Society
(M. arenaria, M. incognita, M. hapla, and M. javanica) (Nicol et al. 1999). These studies have confirmed that rootstock resistance is dependent on nematode species and that there is not a single rootstock resistant to all species from the Meloidogyne genus (Stirling and Cirami 1984). Despite these numerous studies, there is no information regarding the parasitic behavior of the aggressive M. ethiopica nematode against rootstocks frequently used in the wine industry.

In this study, we hypothesized that resistant rootstocks of Vitis would reduce parasitism by $M$. ethiopica. To test this hypothesis, our research objective was to evaluate the efficiency of six distinct rootstocks of Vitis (SO4, 101-14 MG, 110R, 3309C, Kober 5BB, and Harmony) in reducing $M$. ethiopica parasitism under field and greenhouse conditions.

\section{Materials and Methods}

Evaluations of parasitism by $M$. ethiopica were performed under two complementary assay conditions: one under field conditions and another under greenhouse conditions, using the same Vitis rootstocks.

Field tests. The field tests were carried out at a vineyard highly infested with M. ethiopica located in Codigua, Metropolitan Region, Chile. This site was located in the same irrigation sector where Carneiro et al. (2007) identified this aggressive nematode for the first time in Chile using molecular analyses, and confirmed by comparing perineal pattern of females from these populations. The field soil was a very fine sandy loam that was moderately well-drained, presented rapid permeability, was slightly rocky, and had a slope of 0 to $2 \%$.

A randomized completed block design was implemented with seven treatments (six rootstocks and Chardonnay), eight replicates (vines) per treatment, and eight blocks (planted row). The experimental unit was one vine. The experimental planting consisted of eight rows planted with 28 vines with spacing of 1.5 meter between vines $\times 2 \mathrm{~m}$ between rows (Fig. 1). Within each row, one vine of each of the following rootstocks was sampled: $\mathrm{SO} 4(V$. berlandieri $\times V$. riparia $)$, 101-14 MG $(V$. riparia $\times V$. rupestris $), 110 \mathrm{R}(V$. berlandieri $\times$ $V$. rupestris), 3309C $(V$. riparia $\times V$. rupestris), Kober 5BB ( $V$. berlandieri $\times$ V. riparia), Harmony $(1613 \times$ Dogridge $)$, and Chardonnay (Vitis vinifera). One-year-old vines were certified as authentic by their nursery in Curicó, Chile, but were also assessed during the growing season. The vines were watered using furrow irrigation.

Soil samples for each experimental unit were collected three times: before planting ( $\mathrm{P} 0)$ to provide an initial assessment of the M. ethiopica population, at 40 days post-planting (P40), and at 150 days postplanting (P150), when the plants and their surrounding soil were removed from the field. Soil core samples were taken using a $30 \times$ $2.5 \mathrm{~cm}$ auger. Each sample consisted of eight cores taken to a depth 
of $30 \mathrm{~cm}$ from within $15 \mathrm{~cm}$ of the stem of the plant. In total, $56 \mathrm{sam}-$ ples were collected for each sampling date. A total of 168 samples were collected during the course of the study, as obtained from seven treatments with eight replicates per treatment and three sampling dates. The roots of each vine were extracted from the soil with care to minimize losses, particularly of the more fine roots. The roots were then washed and weighed for subsequent galls and egg counts which were determined for the root system. To extract eggs from the gelatinous matrix, commercially available $5.25 \%$ sodium hypochlorite was diluted to $0.5 \%$ using the method described by Barker (1985). A stereoscopic magnifying glass was used to count the eggs. The following measurements were taken: (i) weight (g) of shoots (leaves and lateral branches); (ii) weight (g) of roots; (iii) number of second stage juvenile (J2) and male M. ethiopica extracted from a $250 \mathrm{ml}$ subsample using the Cobb method and a Baermann funnel (Magunacelaya and Dagnino 1999); (iv) number of M. ethiopica eggs in the roots; and (v) number of M. ethiopica galls in the roots.
Analysis of variance (two way ANOVA) was used for statistical analyses $(P \leq 0.05)$ of the following parameters: (i) weight $(\mathrm{g})$ of shoots (leaves and lateral branches); (ii) weight (g) of roots; (iii) number of M. ethiopica J2s; (iv) number of M. ethiopica eggs in the roots; and (v) number of M. ethiopica galls in the roots. Reproductive indices were used to evaluate variations in $\mathrm{J} 2$ nematodes at $\mathrm{P} 40$ and P150 using the equations $\mathrm{P} 40 / \mathrm{P} 0$ (initial population) and $\mathrm{P} 150 / \mathrm{P} 0$, respectively. The reproductive indices represent the population variation of each plant, and the tables present the average of indices for the eight replicates. Prior to ANOVA, population data were $\log _{10}(x+1)$ transformed while the remaining variables were $\log _{10}(\mathrm{x})$ transformed to achieve normal distribution. The Kolmogorov-Smirnov and Levene's tests were used to assess normality and homogeneity of variance, respectively. The multiple comparison Student-Newman-Keuls test was used to separate treatment averages.

Greenhouse tests. The tests were performed at the Faculty of Agricultural Sciences of the Universidad de Chile, Antumapu Campus,

\section{$\mathrm{N}^{\circ}$ of plant}

n!

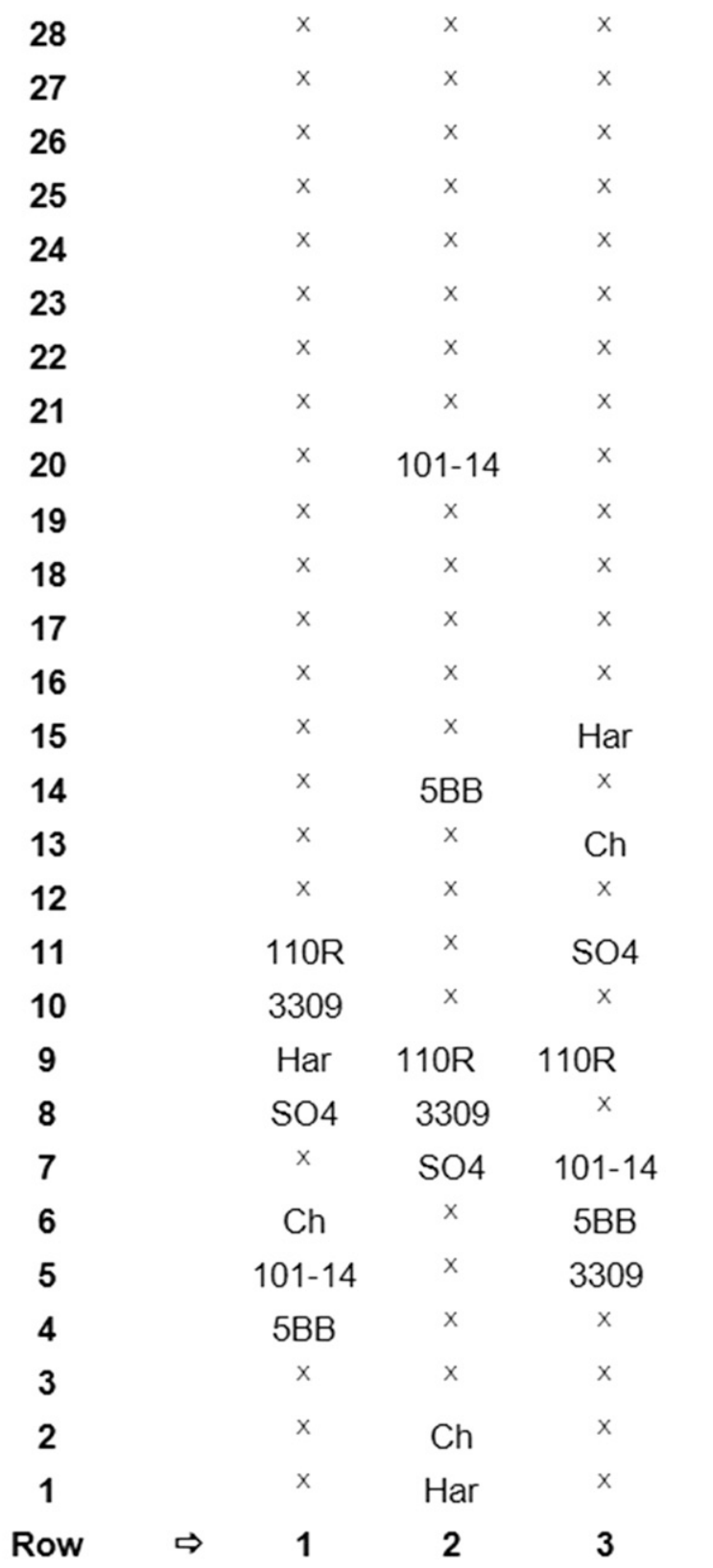

$\times$
$\times$
$\times$
$\times$
$\times$
$\times$
$\times$
$\times$
$\times$

$x$
$x$
$x$
$x$
$x$
$x$
$x$
$x$
$x$
$x$

$x \quad x$

$x \quad x$

$101-14$

$\times \quad \mathrm{Har}$

\section{$5 B B$}

$x \quad x$

$x \quad x$

$x \quad x$

$x$

SO4 101-14

$\times \quad 3309$

Har

$\mathrm{x}$
$\mathrm{Ch}$
$\mathrm{x}$
$\mathrm{x}$

3309

$\begin{array}{cc}x & \text { Ch } \\ \times & \times \\ 3309 & \times \\ \times & 110 R\end{array}$

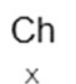

$110 \mathrm{R}$
$\times$
$\mathrm{SO} 4$
5

\begin{tabular}{|c|c|c|}
\hline$x$ & $x$ & $x$ \\
\hline$x$ & $x$ & $x$ \\
\hline SO4 & $x$ & $x$ \\
\hline$x$ & $x$ & $x$ \\
\hline$x$ & $x$ & $x$ \\
\hline$x$ & $x$ & $x$ \\
\hline$x$ & $x$ & $x$ \\
\hline$x$ & $x$ & $x$ \\
\hline$x$ & $x$ & $x$ \\
\hline$x$ & $x$ & $x$ \\
\hline$x$ & $\mathrm{Ch}$ & $x$ \\
\hline$x$ & $5 B B$ & $x$ \\
\hline$x$ & $x$ & $x$ \\
\hline$x$ & $x$ & $x$ \\
\hline$x$ & $x$ & $x$ \\
\hline$x$ & $x$ & $x$ \\
\hline $101-14$ & x & $x$ \\
\hline 5BB & x & $x$ \\
\hline$x$ & $x$ & $x$ \\
\hline $\mathrm{Ch}$ & 3309 & 3309 \\
\hline 3309 & $x$ & $x$ \\
\hline$x$ & Har & $\mathrm{SO} 4$ \\
\hline$x$ & $x$ & $\mathrm{Ch}$ \\
\hline 110R & $110 R$ & 5BB \\
\hline Har & $x$ & $101-14$ \\
\hline$x$ & SO4 & Har \\
\hline$x$ & $x$ & $110 \mathrm{R}$ \\
\hline$x$ & $101-14$ & $x$ \\
\hline 6 & 7 & 8 \\
\hline
\end{tabular}

Fig. 1. Distribution of plants in the field assay, where $x$ represents plants not considered in sampling. SO4, 101-14 (101-14 MG), 110R, 3309 (3309C), 5BB (Kober 5BB), Har (Harmony), and Ch (Chardonnay) represent each evaluated plant (replicate). 
Metropolitan Region, Chile. The tests lasted 180 days. Fourteen vines were used for each rootstock (SO4, 101-14 MG, 110R, 3309C, Kober 5BB, and Harmony) and for the own-root Chardonnay (control), totaling to 98 vines. The field and greenhouse vines were obtained from the same nursery in Curicó, Chile. Each vine was kept in a 2 liter polyethylene bag filled with a steam-sterilized substrate containing $50 \%$ sand and $50 \%$ loam.

The experiment was set up as a completely randomized design, with six rootstocks and control, and two nematode inoculum treatments (0 eggs/vine or 200 eggs/vine) applied to each rootstock. Given the aggression of the nematode, 200 eggs were used per plant.

Infected roots from the self-rooted Chardonnay were collected from the same soil and same irrigation sector as the field test. The roots were transported to the laboratory with humid soil to maintain egg viability. The eggs were extracted from the roots following the method described by Barker (1985). The collected eggs were repeatedly washed with water to eliminate the saline solution and were placed inside a $100 \mathrm{ml}$ test tube. A sample was obtained from the egg suspension, and the number of eggs was counted in a dish using a stereoscopic magnifying glass. The total quantity of eggs in $100 \mathrm{ml}$ was calculated, and this volume was subsequently diluted to make a suspension of $6.7 \mathrm{eggs} / \mathrm{ml}$ (Barker 1985). Once the inoculum was prepared, three holes were made in the soil near each vine, close to areas presenting the most roots. A pipette delivered $10 \mathrm{ml}$ of suspension to each hole, resulting in inoculation with $200 \mathrm{M}$. ethiopica eggs per plant. Watering was conducted to maintain the soil at field capacity.

Six months after inoculation, the following measurements were taken: (i) fresh weight (g) of shoots (leaves and lateral branches); (ii) weight (g) of root system; (iii) number of $\mathrm{J} 2 \mathrm{~s}$ and male $M$. ethiopica nematodes in $250 \mathrm{ml}$ of soil, using the Cobb method and Baermann funnel (Magunacelaya and Dagnino 1999); (iv) number of M. ethiopica eggs in the roots; and (v) number of M. ethiopica galls in the roots. The roots were extracted with care to reduce losses, particularly of fine roots. These were then washed over a 24 mesh $(0.707 \mathrm{~mm}$ opening) sieve, weighed, and stored in hermetic plastic bags with a $90 \%$ alcohol solution for subsequent gall counts and egg extractions. The eggs were extracted from fresh roots using the same methodology as applied for inoculum preparations (Barker 1985).

Three replicates per treatment were used for egg counts, and seven replicates per treatment were used for the remaining variables. An experimental unit was composed by a vine in a 2 liter bag filled with

Table 1. Number of galls and Meloidogyne ethiopica eggs per root system and weight $(\mathrm{g})$ for the shoots and roots in field vines ${ }^{\mathrm{z}}$

\begin{tabular}{lrrrr}
\hline Rootstock & \multicolumn{1}{c}{ Galls } & \multicolumn{1}{c}{ Eggs } & Root & Shoot \\
\hline Harmony & $13.0 \mathrm{c}$ & $11,553.6 \mathrm{~b}$ & $50.9 \mathrm{a}$ & $89.0 \mathrm{a}$ \\
SO4 & $2.1 \mathrm{c}$ & $2,560.8 \mathrm{~b}$ & $39.9 \mathrm{~b}$ & $46.5 \mathrm{~b}$ \\
$101-14 \mathrm{MG}$ & $4.8 \mathrm{c}$ & $11,980.1 \mathrm{~b}$ & $19.2 \mathrm{c}$ & $22.1 \mathrm{~b}$ \\
$110 \mathrm{R}$ & $28.8 \mathrm{c}$ & $37,554.0 \mathrm{~b}$ & $20.1 \mathrm{c}$ & $16.4 \mathrm{~b}$ \\
3309C & $91.3 \mathrm{~b}$ & $57,802.4 \mathrm{~b}$ & $23.4 \mathrm{c}$ & $34.3 \mathrm{~b}$ \\
Kober 5BB & $4.3 \mathrm{c}$ & $4,808.5 \mathrm{~b}$ & $24.8 \mathrm{c}$ & $36.0 \mathrm{~b}$ \\
Chardonnay & $184.9 \mathrm{a}$ & $143,872.1 \mathrm{a}$ & $22.0 \mathrm{c}$ & $9.0 \mathrm{~b}$ \\
\hline
\end{tabular}

${ }^{\mathrm{z}}$ Field data represent the average of eight replicates. Different letters indicate significant differences according to the Student-Newman-Keuls test $(P \leq 0.05)$. soil. Before assessing the data via two way ANOVA $(P \leq 0.05)$, population data were $\log _{10}(\mathrm{x}+1)$ transformed while the remaining variables were $\log _{10}(\mathrm{x})$ transformed to achieve normal distribution. The multiple comparison Student-Newman-Keuls test was used to separate treatment averages.

\section{Results}

Rootstocks reduced $M$. ethiopica parasitism, with less galls and eggs. Significant differences were found for galls $(P \leq 0.001)$ and eggs $(P \leq 0.001)$ when comparing the values obtained for the different rootstocks against the own-root Chardonnay control (Tables 1 and 2). Under field (Table 1) and greenhouse (Table 2) conditions, all rootstocks had lower numbers of galls and eggs than the Chardonnay control. Differences were not detected between rootstocks in the field with respect to egg counts, though rootstock 3309C supported significantly more galls than the others.

All greenhouse-grown rootstocks presented significantly $(P \leq$ 0.001 ) fewer galls as compared with the Chardonnay control (Table 2). Significant differences $(P \leq 0.001)$ were also observed in regards to egg counts between the rootstocks and the Chardonnay control (Table 2). Worth noting, the greenhouse-grown 3309C rootstock presented values similar to the other rootstocks grown under this same condition; in contrast to that found under field conditions (Tables 1 and 2). The noninoculated Chardonnay control did not show any evidence of the presence of damage by $M$. ethiopica, indicating that there was no contamination between treatments.

M. ethiopica $\mathbf{J} 2$ population on rootstocks. The average population levels of $M$. ethiopica in the field were high and uniformly distributed considering the aggressiveness of M. ethiopica (Table 3). In the field, the population indices at 150 days were lower on Harmony, 101-14MG, and Kober 5BB rootstocks than on the Chardonnay control, but the differences were not significant $(P \leq 0.001)$ (Table 4$)$. Under greenhouse conditions, final parasite reproduction (P180/P0) was minimal in the rootstocks as compared with the Chardonnay control $(P \leq 0.001)$ (Table 4). In the greenhouse tests, $M$. ethiopica increased 112-fold in the own-root Chardonnay control, but in field tests the population increased only 1.3 -fold in the control 150 days after planting (Table 4).

At the start of the field tests, males were detected for Harmony, 101-14 MG, and 3309C rootstocks. At the end of the field tests, these same rootstocks, as well as the $110 \mathrm{R}$ rootstock and Chardonnay control, presented male M. ethiopica. At the end of the greenhouse tests, male nematodes were found only in the Chardonnay control.

Effect of M. ethiopica on rootstock and control vine parameters. Considering that the rootstocks presented generally reduced $M$. ethiopica parasitism (i.e., lower quantity of galls and eggs in the roots), rootstock vigor and resistance were estimated at the end of each test (P150 field, P180 greenhouse) by measuring certain vine parameters (i.e., shoot and root weights). In the field tests, the roots of the Harmony and SO4 rootstocks weighed significantly $(P \leq 0.001)$ more than the Chardonnay control and other rootstocks (Table 1). Regarding shoot weight, only the Harmony rootstock supported significantly heavier shoots $(P \leq 0.001)$ as compared with the remaining rootstocks and the Chardonnay control (Table 1). The greenhouse tests evidenced no effects of nematode parasitism on vine parameters. When comparing the inoculated and noninoculated treatments, the values were very

Table 2. Number of galls and Meloidogyne ethiopica eggs per root system and weight (g) for the shoots and roots in greenhouse vines ${ }^{\mathrm{Z}}$

\begin{tabular}{|c|c|c|c|c|c|c|}
\hline Rootstock & Galls & Eggs & Root w/ inoculum & Root w/o inoculum & Shoot w/ inoculum & Shoot w/o inoculum \\
\hline Harmony & $0.14 \mathrm{~b}$ & $77.7 \mathrm{~b}$ & $51.3 \mathrm{a}$ & $45.6 \mathrm{a}$ & $7.2 \mathrm{a}$ & $8.5 \mathrm{a}$ \\
\hline $\mathrm{SO} 4$ & $0.86 \mathrm{~b}$ & $77.7 \mathrm{~b}$ & $46.7 \mathrm{a}$ & $45.9 \mathrm{a}$ & $4.7 \mathrm{a}$ & $5.2 \mathrm{~b}$ \\
\hline 101-14 MG & $0 \mathrm{~b}$ & $77.7 \mathrm{~b}$ & $22.3 \mathrm{~d}$ & $20.3 \mathrm{c}$ & $4.0 \mathrm{ab}$ & $3.3 \mathrm{bc}$ \\
\hline $110 \mathrm{R}$ & $1.29 \mathrm{~b}$ & $155.3 \mathrm{~b}$ & $30.1 \mathrm{c}$ & $31.9 \mathrm{~b}$ & $3.5 \mathrm{ab}$ & $4.0 \mathrm{bc}$ \\
\hline $3309 \mathrm{C}$ & $1.14 \mathrm{~b}$ & $166.3 \mathrm{~b}$ & $23.7 \mathrm{c}$ & $20.6 \mathrm{c}$ & $3.8 \mathrm{ab}$ & $3.1 \mathrm{bc}$ \\
\hline Kober 5BB & $0 \mathrm{~b}$ & $233.0 \mathrm{~b}$ & $34.1 \mathrm{bc}$ & $31.3 \mathrm{~b}$ & $2.6 \mathrm{~b}$ & $2.3 \mathrm{c}$ \\
\hline Chardonnay & $263.71 \mathrm{a}$ & $66,422.0 \mathrm{a}$ & $42.4 \mathrm{ab}$ & $46.3 \mathrm{a}$ & $3.8 \mathrm{ab}$ & $3.4 \mathrm{bc}$ \\
\hline
\end{tabular}

${ }^{\mathrm{z}}$ Greenhouse data represent vines inoculated with 200 eggs/vine. Galls, root, and shoot data correspond to the average of seven replicates and egg data correspond to the average of three replicates. Different letters indicate significant differences according to the Student-Newman-Keuls test $(P \leq 0.05)$. 
similar, indicating that the results were dependent on the characteristics of the rootstock (Table 2).

\section{Discussion}

Resistance is conceptually focused on reducing the nematode population (McKenry and Anwar 2006; Roberts 1992; Trudgill 1991). The present study demonstrated that under field and greenhouse conditions, the rootstocks generally hindered M. ethiopica parasitism of Vitis. Under field conditions, $M$. ethiopica had marked difficulties in parasitizing the six rootstocks as compared with the Chardonnay control, which has demonstrated susceptibility to nematodes of the Meloidogyne genus (Aballay et al. 2012; Howland et al. 2015). These results partially align with those of Gutiérrez-Gutiérrez et al. (2011), a study that found $110 \mathrm{R}$ and SO4 rootstocks of the Cabernet Sauvignon variety to present low quantities of $M$. javanica and M. arenaria galls. Results similar to the present study were also obtained by Somavilla et al. (2012), a study in which the Harmony, Kober 5BB, and SO4 rootstocks of Chardonnay had low quantities of $M$. incognita and $M$. arenaria galls.

A significant difference in population indices of $\mathrm{J} 2$ nematodes was observed in greenhouse-grown rootstocks, which is in line with Aballay and Vilches (2015). However, significant differences in population indices of $\mathrm{J} 2$ nematode were not found at the end of the field tests. The decrease in $\mathrm{J} 2$ nematodes observed for the susceptible Chardonnay control in field test could be explained by Seinhorst (1966), who postulated that a portion of food is used to maintain the present population while the remaining food is used to increase the population. Plant damage would reduce the available amount of food, the population would decrease (Seinhorst 1967), and there would be fewer individuals that reach the adult stage and produce descendants. However, a probable explanation for the lack of differences in $\mathrm{J} 2$ populations is that there was insufficient time for the large population of eggs on self-rooted Chardonnay to hatch. This population sensitivity was evidenced by the appearance of male nematodes, which responded to an adverse, rapid population increase in greenhouse-grown Chardonnay. The nematode population when parasitizing the majority of the field rootstocks included males, which could be an indicator of vine characteristics that make nematode parasitism more difficult. Although the exact strategy of resistance is unknown, the roots of the tested rootstocks were thicker and more rapidly scarred, which could represent a physical barrier against parasitism. This was not detected in the greenhouse condition for the inoculated populations, suggesting that the appearance of males as an indicator of resistance in rootstocks is not immediate. Moreover, it is possible that the root system could impede nematode establishment of a feeding site as sexual destiny is determined shortly after the formation of giant cells (Triantaphyllou 1973). This possibility is supported by Tordable et al. (2012), who reported that M. ethiopica is able to establish a feeding site in a Cabernet Sauvignon variety that, according to Magunacelaya (2010), shows a degree of a nematode tolerance.

Results of the greenhouse experiment supported the results of the field experiment in that all rootstocks were less heavily parasitized, and had lower egg populations, than the self-rooted Chardonnay. It

Table 3. Number of Meloidogyne ethiopica second stage juveniles in $250 \mathrm{ml}$ of soil from the field and greenhouse assays

\begin{tabular}{lrrrrrr}
\hline & \multicolumn{3}{c}{ Field $^{\mathbf{y}}$} & & \multicolumn{2}{c}{ Greenhouse $^{\mathbf{z}}$} \\
\cline { 2 - 3 } Rootstock & \multicolumn{1}{c}{ P0 } & P40 & P150 & & P0 & P180 \\
\hline Harmony & 958.2 & 506.7 & 358.6 & & 25 & 0 \\
SO4 & 497.1 & 333.6 & 572.6 & & 25 & 0.7 \\
101-14 MG & $1,011.0$ & $1,090.1$ & 420.5 & & 25 & 2.4 \\
110 R & 820.6 & $1,649.5$ & 757.7 & & 25 & 7.6 \\
3309C & 416.5 & $1,640.8$ & 952.6 & & 25 & 7.4 \\
Kober 5BB & 956.2 & 876.3 & 368.3 & & 25 & 0 \\
Chardonnay & $1,109.8$ & $1,741.3$ & 825.1 & & 25 & $2,808.0$ \\
\hline
\end{tabular}

${ }^{y}$ Field data represent the average of eight replicates. P0, J2 population before planting; P40, J2 population 40 days post-planting; P150, J2 population 150 days post-planting.

${ }^{\mathrm{z}}$ Greenhouse data represent the average of eight replicates. P0, J2 population inoculated; P180, J2 population 180 days post-inoculated. is probable that the inoculum preparation and application, nematode adaptation to greenhouse conditions, and the influence of rootstocks strongly reduced the parasitic capacity of M. ethiopica. Stirling and Cirami (1984) suggested that greenhouse-grown resistant rootstocks would be resistant or tolerant under field conditions, which supports the differences found in the present study.

The effects of $M$. ethiopica parasitism were not reflected in the root and shoot weights of Harmony and SO4 rootstocks. Indeed, these rootstocks weighed notably more than the other rootstocks despite presenting similar quantities of nematode galls and eggs. This could indicate that there is either no relationship between vigor and resistance and/or that the duration of nematode exposure was too short to consistently effect rootstock growths. The greenhouse results evidenced that $M$. ethiopica parasitism was hindered by all of the rootstocks, and after 180 days, the nematodes did not affect vine parameters, with similar weights found between inoculated and noninoculated rootstocks. High rootstock vigor is not useful in the wine industry, which prefers rootstocks with less vigor so that the nutrients absorbed by the root go to the fruit and, consequently, provide better wine quality (Dry and Loveys 1998). Likewise, less vigorous rootstocks are the most recommended for use in valleys and fertile soil (Stockert and Smart 2008). Moreover, Kober 5BB rootstock was recently reported as compatible with numerous wine varieties (Vršič et al. 2015). Future studies are needed to determine the use of the assessed rootstocks over the long-term, when surviving nematode generations may be more aggressive, and in distinct climate and soil conditions, as both rootstock resistance and nematode survival and reproduction could be affected by these factors.

In conclusion, despite the aggressiveness of M. ethiopica, the present results support the use of rootstocks as an efficient approach to managing this harmful nematode species. The 3309C rootstock is the least recommended for field use, because this study indicates that 3309C rootstock is susceptible to M. ethiopica, which supports previous studies finding this rootstock to be moderately susceptible to other Meloidogyne species (Ferris et al. 2012; McKenry and Anwar 2006). The selection of one or more of the evaluated rootstocks for agricultural use should not depend solely on the presence of this new nematode species, but also on the soil type and climate conditions, together with the type of crop or grape quality. These factors are important to consider as each rootstock has different characteristics, where, for example, vigorous rootstocks would negatively affect wine quality. It is due to this that $M$. ethiopica treatment through the use of Harmony, SO4, 101-14 MG, 110R, or Kober 5BB should adjust to the needs of winegrower. Our results provide valuable information on the behavior of the parasitic M. ethiopica, a species that has recently been noted for its aggressiveness, being placed on the 2011 alert list of the European and Mediterranean Plant Protection Organization. Therefore, the use of rootstocks resistant to $M$. ethiopica is a viable treatment

Table 4. Population indices of Meloidogyne ethiopica in soil from field and greenhouse tests

\begin{tabular}{|c|c|c|c|}
\hline \multirow[b]{2}{*}{ Rootstock } & \multicolumn{2}{|c|}{ Field ${ }^{y}$} & \multirow{2}{*}{$\frac{\text { Greenhouse }^{\mathrm{z}}}{\text { P180/P0 }}$} \\
\hline & P40/P0 & P150/P0 & \\
\hline Harmony & $1.0 \mathrm{~b}$ & $0.8 \mathrm{~b}$ & $0 \mathrm{~b}$ \\
\hline $\mathrm{SO} 4$ & $0.9 \mathrm{~b}$ & $1.3 \mathrm{ab}$ & $0 \mathrm{~b}$ \\
\hline 101-14 MG & $1.7 \mathrm{~b}$ & $0.7 \mathrm{~b}$ & $0.1 \mathrm{~b}$ \\
\hline $110 \mathrm{R}$ & $2.7 \mathrm{~b}$ & $1.6 \mathrm{ab}$ & $0.3 \mathrm{~b}$ \\
\hline $3309 \mathrm{C}$ & $6.3 \mathrm{a}$ & $3.1 \mathrm{a}$ & $0.3 \mathrm{~b}$ \\
\hline Kober 5BB & $2.9 \mathrm{~b}$ & $0.6 \mathrm{~b}$ & $0 \mathrm{~b}$ \\
\hline Chardonnay & $4.0 \mathrm{~b}$ & $1.3 \mathrm{ab}$ & $112.3 \mathrm{a}$ \\
\hline
\end{tabular}

${ }^{\mathrm{y}}$ Field data represent the average of eight replicates. $\mathrm{P} 40 / \mathrm{P} 0=$ population index at 40 days; $\mathrm{P} 150 / \mathrm{P} 0=$ population index at the end of the test period, 150 days. The reproductive indices represent population variation for each plant, and the presented values are the average of indices for eight replicates. Different letters indicate significant differences according to the StudentNewman-Keuls test $(P \leq 0.001)$.

${ }^{\mathrm{z}}$ Greenhouse data represent the average of seven replicates. $\mathrm{P} 180 / \mathrm{P} 0=$ population index at the end of the test period, 180 days. Different letters indicate significant differences according to the Student-Newman-Keuls test $(P \leq 0.001)$. 
alternative for vineyards both locally and worldwide. From a nematological perspective, the evaluated rootstocks are promising alternatives for use in the control and management of M. ethiopica and in integrated nematode management programs. Indeed, these rootstocks can complement rootstocks with other control strategies (e.g., chemical, biological, guano, etc.).

\section{Acknowledgments}

We thank to project PIUAs PUCV 037.293/2015 and BIOPUB (Dr. Eduardo Fuentes and Ashley VanCott) for help with formal aspects of this paper.

\section{Literature Cited}

Aballay, E., Ordenes, P., Mårtensson, A., and Persson, P. 2012. Effects of rhizobacteria on parasitism by Meloidogyne ethiopica on grapevines. Eur. J. Plant Pathol. 135:137-145.

Aballay, E., and Vilches, O. 2015. Resistance assessment of grapevine rootstocks used in Chile to the root-knot nematodes Meloidogyne ethiopica, M. hapla, and M. javanica. Cienc. Investig. Agrar. 42:407-413.

Anwar, S. A., McKenry, M. V., and Faddoul, J. 2000. Reproductive variability of field populations of Meloidogyne spp. on grape rootstocks. J. Nematol. 32:265-270.

Aydınlı, G., Mennan, S., Devran, Z., Sirca, S., and Urek, G. 2013. First report of the root-knot nematode Meloidogyne ethiopica on tomato and cucumber in Turkey. Plant Dis. 97:1262.

Barker, K. R. 1985. Nematode Extraction and Bioassays. Page 223 in: An Advanced Treatise on Meloidogyne,Vol. 2: Methodology. K. R. Barker, C. C. Carter, and J. N. Sasser. eds. Department of Plant Pathology, North Carolina State University.

Carneiro, R. M. D. G., Almeida, M. R. A., Cofcewicz, E. T., Magunacelaya, J. C., and Aballay, E. 2007. Meloidogyne ethiopica, a major root-knot nematode parasitising Vitis vinifera and other crops in Chile. Nematology 9:633-639.

Carneiro, R. M. D. G., Gomes, C. B., Almeida, M. R. A., Gomes, A. C. M. M., and Martins, I. 2003. Primeiro registro de Meloidogyne ethiopica Whitehead, 1968, em plantas de quivi no Brasil e reação a diferentes plantas cultivadas. Nematol. Bras. 27:151-158.

Carneiro, R. M. D. G., Randig, O., Almeida, M. R. A., and Gomes, A. C. M. M. 2004. Additional information on Meloidogyne ethiopica Whitehead, 1968 (Tylenchida: Meloidogynidae), a root-knot nematode parasiting kiwi fruit and grape-vine from Brazil and Chile. Nematology 6:109-123.

Conceição, I. L., Tzortzakakis, E., Gomes, P., Abrantes, I., and da Cunha, M. J. 2012. Detection of the root-knot nematode Meloidogyne ethiopica in Greece. Eur. J. Plant Pathol. 134:451-457.

Dry, P. R., and Loveys, B. R. 1998. Factors influencing grapevine vigour and the potential for control with partial rootzone drying. Aust. J. Grape Wine Res. 4:140-148.

EPPO. 2015. PQR - EPPO database on quarantine pests. Online: http://www.eppo. int. Accessed 2016.

Ferris, H., Zheng, L., and Walker, M. 2012. Resistance of grape rootstocks to plant-parasitic nematodes. J. Nematol. 44:377-86.

Gutiérrez-Gutiérrez, C., Palomares-Rius, J. E., Jiménez-Díaz, R. M., and Castillo, P. 2011. Host suitability of Vitis rootstocks to root-knot nematodes (Meloidogyne spp.) and the dagger nematode Xiphinema index, and plant damage caused by infections. Plant Pathol. 60:575-585.

Howland, A. D., Skinkis, P. A., Wilson, J. H., Riga, E., Pinkerton, J. N., Schreider, R. P., and Zasada, I. A. 2015. Impact of grapevine (Vitis vinifera) varieties on reproduction of the northern root-knot nematode (Meloidogyne hapla). J. Nematol. 47:141-147.

Hunt, D. J., and Handoo, Z. A. 2009. Root knot nematodes: taxonomy, identification and principal species. Pages 55-97 in: Root Knot Nematodes. R. N. Perry, M. Moens, and J. L. Starr, eds. CAB International, Wallingford, U.K.
Karssen, G., and Moens, M. 2006. Root-knot nematodes. Pages 59-90 in: Plant Nematology. R. N. Perry and M. Moens, eds. CAB International, London, U.K

Magunacelaya, J. C. 2004. Nemátodos. Cómo resolver el problema de raíz. Vitivinicultura 13:12-18

Magunacelaya, J. C. 2010. Estrategias de manejo de nematodos fitoparásitos de importancia agrícola en Chile. Rev. Frutic. 3:24-35.

Magunacelaya, J. C., and Dagnino, E. 1999. Nematología Agrícola en Chile. Serie Ciencias Agronómicas N². Universidad de Chile, Santiago, Chile.

McKenry, M. V., and Anwar, S. 2006. Nematode and grape rootstock interactions including an improved understanding of tolerance. J. Nematol. 38:312-318.

Murga-Gutiérrez, S. N., Colagiero, M., Rosso, L. C., Finetti-Sialer, M. M., and Ciancio, A. 2012. Root-knot nematodes from asparagus and associated biological antagonists in Peru. Nematropica 42:57-62.

Nicol, J. M., Stirling, G. R., Rose, B. J., May, P., and Van Heeswijck, R. 1999. Impact of nematodes on grapevine growth and productivity: current knowledge and future directions, with special reference to Australia viticulture. Aust. J. Grape Wine Res. 5:109-127.

Pérez, J. 1991. Uso potencial de portainjertos en vides para uva de mesa en Chile. Aconex 31:21-27.

Rivera, L., and Aballay, E. 2008. Nematicide effect of various organic soil amendments on Meloidogyne ethiopica WHITEHEAD, 1968, on potted vine plants. Chil. J. Agric. Res. 68:290-296.

Roberts, P. A. 1992. Resistance in nematodes: Definition, concepts and consequences. Pages 1-15 in: Methods for Evaluating Plant Species for Resistance to Plant Parasitic Nematodes. J. L. Starr, ed. Society of Nematologists, Hyattsville, MD

Seinhorst, J. W. 1966. The relationships between population increase and population density in plant parasitic nematodes. I. Introduction and migratory nematodes. Nematologica 12:157-169.

Seinhorst, J. W. 1967. The relationships between population increase and population density in plant parasitic nematodes. V. Influence of damage to the host on multiplication. Nematologica 13:481-492.

Šrca, S., Urek, G., and Karssen, G. 2004. First report of the root-knot nematode Meloidogyne ethiopica on tomato in Slovenia. Plant Dis. 88:680.

Smiley, R. 2005. Plant-parasitic nematodes affecting wheat yield in the Pacific Northwest. Online: http://ir.library.oregonstate.edu/xmlui/handle/1957/20387. Oregon State University Extension Service, Corvallis, OR

Somavilla, L., Gomes, C., and Quecini, V. 2012. Registro da ocorrência de Meloidogyne incognita no porta-enxerto 'IAC 766-Campinas' no estado de Pernambuco e reação de porta-enxertos e de cultivares copa de videira a Meloidogyne spp. Rev. Bras. Frutic. 34:750-756.

Stirling, G. R., and Cirami, R. M. 1984. Resistance and tolerance of grape rootstocks to South Australian populations of root-knot nematode. Aust. J. Exp. Agric. Anim. Husb. 24:277-282.

Stockert, C. M., and Smart, D. R. 2008. The physiological basis of rootstock control of grape fruit nitrogen composition. Pages 78-79 In: Proceedings for the 2nd Annual National Viticulture Research Conference. University of California, Davis.

Strajnar, P., Sirca, S., Stare, B. G., and Urek, G. 2009. Characterization of the rootknot nematode, Meloidogyne ethiopica Whitehead, 1968, from Slovenia. Russ. J. Nematol. 17:135-142.

Tordable, M., Lax, P., Magunacelaya, J. C., and Ducet, M. 2012. Histopathological analysis of roots of Vitis vinifera cultivar Cabernet Sauvignon infected with Meloidogyne ethiopica. Nematropica 42:276-280.

Triantaphyllou, A. C. 1973. Environmental sex differentiation of nematodes in relation to pest management. Annu. Rev. Phytopathol. 11:441-462.

Trudgill, D. L. 1991. Resistance to and tolerance of plant-parasitic nematodes in plants. Annu. Rev. Phytopathol. 29:167-192.

Vršič, S., Pulko, B., and Kocsis, L. 2015. Factors influencing grafting success and compatibility of grape rootstocks. Sci. Hortic. (Amsterdam) 181:168-173. 